\title{
Effects of Endogenously Produced Leukotrienes, Thromboxane, and Prostaglandins on Coronary Vascular Resistance in Rabbit Myocardial Infarction
}

Alex S. Evers, Sidney Murphree, Jeffrey E. Saffitz, Barbara A. Jakschik, and Philip Needleman

Departments of Anesthesiology, Pathology, and Pharmacology, Washington University School of Medicine, St. Louis, Missouri 63110

\begin{abstract}
In an effort to evaluate the synthesis and function of eicosanoids in myocardial infarction, we have developed a technique of in vivo myocardial infarction in rabbits followed by ex vivo cardiac perfusion. Isolated Langendorff perfused infarcted hearts (removed 1 or $4 \mathrm{~d}$ after infarction) responded to the inflammatory cell agonist $\boldsymbol{N}$-formylmethionyl-leucyl-phenylalanine (fMLP) with (a) the release of leukotrienes $B_{4}, C_{4}$, and $D_{4} ;(b)$ the release of large amounts of thromboxane $(235 \pm 66 \mathrm{ng} / 5 \mathrm{~min})$, prostacyclin (714 $285 \mathrm{ng} / 5 \mathrm{~min})$, and prostaglandin $\mathrm{E}_{\mathbf{2}}\left(\mathrm{PGE}_{2}\right)$ $(330 \pm 108 \mathrm{ng} / 5 \mathrm{~min})$; and (c) a coronary vasoconstriction (21.1 $\pm 2.5 \%$ increase in coronary perfusion pressure) that was specifically inhibited by the peptidoleukotriene receptor antagonist FPL-55712. While noninfarcted hearts challenged with fMLP also released leukotrienes $B_{4}, C_{4}$, and $D_{4}$, they released only small amounts of the cyclooxygenase products (thromboxane, $30 \pm 9 \mathrm{ng} / 5 \mathrm{~min}$; prostacyclin, $120 \pm 54 \mathrm{ng} / 5 \mathrm{~min} ; \mathrm{PGE}_{2}$, $27 \pm 10 \mathrm{ng} / 5 \mathrm{~min}$ ) and showed minimal vasoconstriction $(5.6 \pm 2.1 \%$ increase in perfusion pressure). Similarly, hearts challenged with fMLP $30 \mathrm{~d}$ following infarction released only small amounts of the cyclooxygenase products (thromboxane, $42 \pm 8 \mathrm{ng} / 5 \mathrm{~min}$; prostacyclin, 386 $\pm 31 \mathrm{ng} / 5 \mathrm{~min} ; \mathrm{PGE}_{2}, 79 \pm 25$ $\mathrm{ng} / 5 \mathrm{~min}$ ). When bradykinin was administered, no leukotrienes were produced, but acutely infarcted hearts released 10 times more thromboxane, prostacyclin, and $\mathrm{PGE}_{2}$ than normal hearts and significantly larger amounts of these products than 30-d infarcted hearts. Histologic analysis showed no inflammatory cells in normal hearts, a prominent polymorphonuclear leukocyte infiltration in 1-d infarcted tissue, fibroblast proliferation with mononuclear cell invasion in 4-d infarcted tissue, and a fibrotic scar with scanty mononuclear cell infiltrate in 30-d infarcted tissue. Inflammatory cell invasion was temporarily associated with augmented cyclooxygenase metabolism, suggesting that infiltrating leukocytes may be responsible for production of thromboxane, prostacyclin, and $\mathbf{P G E}_{2}$ in acutely infarcted hearts. The finding that endogenously produced peptidoleukotrienes are potent coronary vasoconstrictors in infarcted rabbit hearts suggests that these products may contribute to tissue injury in myocardial infarction.
\end{abstract}

Portions of this work were presented at the Federation of American Societies for Experimental Biology meeting in St. Louis, MO, April 1984.

Address correspondence and reprint requests to Dr. Needleman, Department of Pharmacology, Washington University School of Medicine, 660 South Euclid Avenue, St. Louis, MO 63110.

Received for publication 12 June 1984 and in revised form 29 October 1984.

J. Clin. Invest.

(c) The American Society for Clinical Investigation, Inc.

0021-9738/85/03/992/08 $\$ 1.00$

Volume 75, March 1985, 992-999

\section{Introduction}

After myocardial infarction, inflammatory cells invade the injured tissue removing necrotic debris. While this function is important to healing, recent investigations have shown that leukocyte depletion before coronary occlusion results in reduced infarct size $(1,2)$. These observations suggest that leukocytes or their metabolic products may increase tissue injury in myocardial infarction. The predominant inflammatory cell types seen in infarcted myocardium are polymorphonuclear leukocytes (PMN) ${ }^{1}$ and macrophages (3). In infarcted tissue, these cells undergo functional and biochemical alterations leading to the generation of highly reactive oxygen species (4), the release of proteolytic lysosomal enzymes (5), and the release of arachidonic acid (AA) from phospholipids (6). The liberated arachidonic acid can be metabolized by the cyclooxygenase pathway to prostaglandins and thromboxane $A_{2}\left(\operatorname{TxA}_{2}\right.$; 7) or by lipoxygenase pathways to hydroxy-eicosatetraenoic acids (HETEs), and leukotrienes (8).

Attention has recently been focused on the role of lipoxygenase products in myocardial infarction by the observation that BW-755C, an inhibitor of both cyclooxygenase and lipoxygenase pathways, reduces canine infarct size $(9,10)$. This is in contrast to previous studies with cyclooxygenase inhibitors, showing that aspirin (11) and naproxen (12) are not cardioprotective and that indomethacin may even increase tissue injury (13). The lipoxygenase products of PMNs and macrophages in both humans and rabbits include the leukotrienes. PMNs produce primarily leukotriene $\mathrm{B}_{4}\left(\mathrm{LTB}_{4} ; 14\right)$, a highly potent chemotactic agent, whereas macrophages produce predominantly leukotrienes $\mathrm{C}_{4}$ and $\mathrm{D}_{4}\left(\mathrm{LTC}_{4}, \mathrm{LTD}_{4} ; 15\right)$. Exogenously administered $\mathrm{LTC}_{4}$ and $\mathrm{LTD}_{4}$ are coronary vasoconstrictors in a variety of species (16-18) and may also have negative inotropic effects (19). Although leukotriene production has not previously been demonstrated in myocardial infarction, we hypothesized that since infiltrating inflammatory cells synthesize these products, leukotrienes might play an important pathophysiologic role in myocardial infarction.

We have developed an isolated perfused infarcted rabbit heart preparation to identify and quantitate the arachidonate metabolites produced by infarcted myocardium. This model provides the ability to collect the effluent draining from infarcted tissue following selective agonist administration, and eliminates the problem of blood interference in the extraction and immunoassay of AA metabolites. The chemotactic peptide $N$-formylmethionyl-leucyl-phenylalanine (fMLP) was administered to these hearts to stimulate the AA metabolism of

1. Abbreviations used in this paper: AA, arachidonic acid; BK, bradykinin; CPP, coronary perfusion pressure; fMLP, $N$-formylmethionylleucyl-phenylalanine; HETES, hydroxy-eicosatetraenoic acids; HPLC, high pressure liquid chromatography; LT, leukotriene; PG, prostaglandin; PMN, polymorphonuclear leukocytes; Tx, thromboxane. 
inflammatory cells in the infarcted tissue. Bradykinin (BK), an agent known to stimulate cardiac prostaglandin synthesis, was also administered (20). Using this preparation, we now report the production of both cyclooxygenase products and leukotrienes by infarcted myocardium and their effects on coronary vascular resistance.

\section{Methods}

Materials. $\left[{ }^{3} \mathrm{H}\right]$ Prostaglandin (PG) $\mathrm{E}_{2},\left[{ }^{3} \mathrm{H}\right] \mathrm{TxB}_{2},\left[{ }^{3} \mathrm{H}\right] 6-$ keto-PGF $_{1 \alpha}$ (all $100 \mathrm{Ci} / \mathrm{mmol})$, and $\left[{ }^{3} \mathrm{H}\right] \mathrm{LTC}_{4}(35.7 \mathrm{Ci} / \mathrm{mmol})$ were purchased from New England Nuclear (Boston, MA). Prostaglandin standards were the gift of Dr. John Pike of the Upjohn Co. (Kalamazoo, MI); synthetic $\mathrm{LTB}_{4}, \mathrm{LTC}_{4}$, and $\mathrm{LTD}_{4}$ were the gift of Dr. J. Rokach of MerckFrosst Laboratories (Dorval P.Q., Canada); FPL-55712 was the gift of Fisons Pharmaceuticals (Leicestershire, United Kingdom); indomethacin was a gift of Merck, Sharp \& Dohme (Rahway, NJ); and OKY-1581 was a gift of Ono Pharmaceuticals (Osaka, Japan). LTC $_{4}$ antisera was kindly supplied by Dr. R. Bell (Riker Laboratories, St. Paul, MN); fMLP and triphenyl tetrazolium chloride were purchased from Sigma Chemical Co. (St. Louis, MO), and BK was purchased from BoehringerMannheim (Indianapolis, IN).

Surgical myocardial infarction. Male New Zealand white rabbits (2-3 kg) were anesthetized with pentobarbital sodium $(30 \mathrm{mg} / \mathrm{kg}$ i.v.). A tracheostomy was performed and the animals were ventilated with $100 \%$ oxygen. The heart was exposed by a transverse thoracotomy at the fourth intercostal space. The distal left circumflex coronary artery was ligated with a 5-0 Prolene suture over a piece of polyethylene tubing (PE-50, Clay-Adams Div., Becton-Dickinson and Co., Parsippany, NJ), resulting in a clearly demarcated blanched area at the apex of the heart. After $60 \mathrm{~min}$, the PE-50 tubing was removed, effecting reperfusion. This resulted in visible hyperemia in the previously blanched area. The chest was closed in layers, the tracheostomy repaired, and the animals allowed to convalesce for either 1,4 , or $30 \mathrm{~d}$.

Heart perfusion and bioassay. After the convalescence period, the animals were reanesthetized (pentobarbital, $30 \mathrm{mg} / \mathrm{kg}$ i.v.), heparin was administered (500 units i.v.), and the hearts were excised and placed in ice-cold Krebs-Henseleit buffer. The aorta was rapidly cannulated, and the hearts were placed in a warming jacket and perfused (Langendorff technique) with oxygenated $\left(\mathrm{O}_{2} / \mathrm{CO}_{2} ; 95 \%: 5 \%\right)$ Krebs-Henseleit buffer at $37^{\circ} \mathrm{C}$ and $25 \mathrm{ml} / \mathrm{min}$. The coronary effluent was allowed to flow directly over three smooth muscle assay organs: guinea pig ileum to detect peptidoleukotriene-like activity, chick rectum to detect $\mathrm{PGE}_{2}$-like activity, and rabbit thoracic aorta to detect thromboxane-like activity. The bioassay organs were standardized to known doses of authentic prostaglandins and leukotrienes. Peptidoleukotrienes were quantitated by interpolating the height (centimeters) of guinea pig ileum contraction to the height of ileal contraction caused by $\operatorname{LTD}_{4}$ standards $(10,30$, and $100 \mathrm{ng})$. A mixture of antagonists was added to the superfusion fluid (below the heart) to render the assay tissues insensitive to catecholamines, acetylcholine, serotonin, and histamine (21). The contraction of the smooth muscle strips was measured with Harvard 386 myographs (Harvard Apparatus Co., South Natick, MA) and monitored on a Soltec DB recorder (Sun Valley, CA). 125-ml (5-min) samples of effluent were collected before and after intracoronary bolus administration of fMLP or BK. A 1-ml aliquot of the effluent was saved and frozen $\left(-20^{\circ} \mathrm{C}\right)$ for subsequent radioimmunoassay (RIA), and the remainder of the effluent was extracted (as described below) for separation by high performance liquid chromatography (HPLC). At the end of each experiment, the hearts were perfused with $100 \mathrm{ml}$ of $1 \%$ triphenyl tetrazolium chloride to confirm infarction.

$H P L C$. Extraction of the leukotrienes was performed by a modification of the method of Powell (22). 125-ml samples of coronary effluent were acidified to $\mathrm{pH} 6.2$ with $\mathrm{HCl}$ and applied to a 2-g openbed, preactivated C-18 octadecysilyl column (J. T. Baker Chemical
Co., Phillipsbury, NJ). The column was washed with water and petroleum ether, and the products were eluted with $15 \mathrm{ml}$ of $100 \%$ methanol. The methanol was evaporated under nitrogen, and the products were resuspended in $1.0 \mathrm{ml}$ of water at $\mathrm{pH} 6.2$ and loaded in the 2.0-ml injection loop of a Beckman Model 110A liquid chromatograph (Beckman Instruments, Fullerton, CA). The products were eluted with a mobile phase of methanol/water/acetic acid (68:32: $0.08), \mathrm{pH} 6.2$, at a flow rate of $1.0 \mathrm{ml} / \mathrm{min}$. Products were detected with a Hitachi 100-10 UV detector set at $280 \mathrm{~nm}$ to detect the conjugated trienes of leukotrienes, and an Absorbance Unit Full Scale of 0.01 . Ultraviolet spectra $(250-300 \mathrm{~nm})$ were obtained on selected peaks using a Beckman DU-8 scanning spectrophotometer (Beckman Instruments). Retention times for the leukotrienes were determined by running authentic standards of $\mathrm{LTB}_{4}, \mathrm{LTC}_{4}$, and $\mathrm{LTD}_{4}$ in the same system.

RIA. $\mathrm{PGE}_{2}, \mathrm{TxB}_{2}$, and 6-keto- $\mathrm{PGF}_{1 \alpha}$ were immunoassayed as previously described (23). The cross reactivities at $50 \%$ displacement of other prostaglandins with the antisera were as follows: $(a) \mathrm{PGE}_{2}$ antiserum: 6-keto-PGF $\mathrm{PG}_{1 \alpha}, 0.39 \% ; \mathrm{PGF}_{2 \alpha}, 0.04 \% ; \mathrm{TxB}_{2}, 0.003 \% ;(b)$ $\mathrm{TxB}_{2}$ antiserum: 6-keto-PGF ${ }_{1 \alpha}, 0.009 \%$; $\mathrm{PGE}_{2}, 0.012 \% ; \mathrm{PGF}_{2 \alpha}, 0.025 \%$; and (c) 6-keto-PGF ${ }_{1 \alpha}$ antiserum: $\mathrm{PGE}_{2}, 0.057 \%$; $\mathrm{TxB}_{2},<0.08 \%$; $\mathrm{PGF}_{2 \alpha}$, $0.14 \%$. The buffer solution used for cardiac perfusion did not alter the immunoassay standard curves for $\mathrm{TxB}_{2}, \mathrm{PGE}_{2}$, or 6-keto-PGF $\mathrm{P}_{1 \alpha}$.

The $\mathrm{LTC}_{4}$ antisera (Bell, R. L., and K. Heghirian, manuscript submitted for publication) had the following cross reactivities at $50 \%$ displacement: PGE $2, \mathrm{PGF}_{2 \alpha}, \mathrm{TxB}_{2}, \mathrm{PGA}_{2}, \mathrm{PGD}_{2}$, 5-HETE, 12-HETE, 9-HETE, 11-HETE, $\mathrm{LTB}_{4}, \mathrm{AA}$, and glutathione $<0.01 \%$ (22); $\mathrm{LTD}_{4}$, $50 \%$; and $\mathrm{LTE}_{4}, 8 \%$. Accordingly, immunoassayable material is referred to as peptidoleukotriene.

The protocol for the $\mathrm{LTC}_{4}$ RIA follows. Incubations for RIA contained (in a total volume of $0.2 \mathrm{ml}$ ): $\mathrm{LTC}_{4}, 16.7-300 \mathrm{pg}$, or coronary effluent up to $0.1 \mathrm{ml} ; 0.01 \mathrm{M}$ Tris buffer, $\mathrm{pH} 7.3$, containing $0.14 \mathrm{M} \mathrm{NaCl}$ and $0.1 \%$ gelatin; antiserum, 1:2,000 dilution; and $\left[{ }^{3} \mathrm{H}\right] \mathrm{LTC}_{4} 3,000 \mathrm{cpm}$. Tubes were placed in the cold for $18 \mathrm{~h}$ and then dextran-coated charcoal $(0.5 \%$ dextran, $0.5 \%$ charcoal) was added to all tubes which were then centrifuged for $10 \mathrm{~min}$ at $3,000 \mathrm{rpm}$. The supernatant was decanted into RPI 3A70B scintillation cocktail (Research Products International, Mt. Prospect, IL) and counted on a Packard 460C scintillation counter (Packard Instrument Co., Downers Grove, IL). Coronary effluent up to $0.1 \mathrm{ml}$ did not displace the standard curve.

Coronary resistance studies. Normal, 1-d, and 4-d infarcted hearts were cannulated and perfused as described above. Mean coronary perfusion pressure was monitored via a sidearm in the perfusion apparatus using a Statham P23dB pressure transducer and a Gould 440 brush recorder (Gould Inc., Santa Clara, CA). The hearts were challenged every $20 \mathrm{~min}$ with intracoronary doses $(0.1 \mathrm{ml})$ of fMLP (100 $\mathrm{ng}$ ) and BK (300 $\mathrm{ng})$, in the absence and in the presence of the leukotriene receptor antagonist FPL-55712 $(0.4 \mu \mathrm{g} / \mathrm{ml})$, the thromboxane synthetase inhibitor OKY-1581 $(0.1 \mathrm{mg} / \mathrm{ml})$, or indomethacin $(1.0 \mu \mathrm{g} /$ $\mathrm{ml})$. The adequacy of thromboxane synthetase inhibition and cyclooxygenase inhibition was confirmed by RIA; adequacy of leukotriene receptor blockade was determined by guinea pig ileum superfusion bioassay.

Histology. At the completion of perfusion studies, infarct size and location were assessed grossly with tetrazolium staining. Hearts were then submerged in $10 \%$ sodium phosphate-buffered formalin and sampled after fixation. Transmural slices of myocardium were taken so as to include both infarcted and normal tissue from the apex to the base of the ventricles. Histologic sections were dehydrated in ethanol, embedded in paraffin and $5-\mu \mathrm{m}$ sections were cut. Sections were stained with hematoxylin and eosin and examined with a light microscope.

\section{Results}

Gross and histologic analysis. Gross inspection of the infarcted hearts showed an area of blanched myocardium with gross 
intramyocardial hemorrhage at the apex of the heart. The infarcted area comprised $20-30 \%$ of the left ventricle on a wet weight basis. The infarcted area did not stain with tetrazolium, whereas the normal areas of the ventricle stained brightly with this dye. In control (normal) hearts, apparently normal myocytes were compactly arranged around intact blood vessels and scattered interstitial fibroblasts. Some sections showed a mild interstitial edema but normal hearts were virtually devoid of inflammatory infiltrates (Fig. 1). In infarcted areas from hearts studied $24 \mathrm{~h}$ postocclusion, extensive zones of coagulation necrosis were seen. Necrosis was transmural in many sections and was accompanied by a variable degree of interstitial hemorrhage. The predominant inflammatory cell at this time was the PMN. Large numbers of PMNs were seen surrounding degenerating necrotic myocardial fibers. Macrophages and fibroblasts were present but were quite rare in comparison to PMNs. Large transmural zones of necrosis with extensive hemorrhage were also seen in hearts studied $4 \mathrm{~d}$ after occlusion. Many sections displayed a centrally located core of necrotic myocardium and erythrocyte debris surrounded by a broad zone of reparative change. The inflammatory infiltrate at $4 \mathrm{~d}$ consisted of large numbers of macrophages and fibroblasts, but few neutrophils. Some sections showed a substantial degree of dystrophic calcification. By $30 \mathrm{~d}$ of age, the infarcts were composed entirely of maturing granulation tissue containing fibroblasts, blood vessels, and abundant extracellular collagen. All necrotic muscle had been resorbed and residual inflammatory cells were limited to occasional nests of pigment-laden macrophages.

Bioassay and RIA. When fMLP was administered to either normal or infarcted hearts, a substance was released that contracted guinea pig ileum (Fig. 2). Release of this substance was dose-dependent over a range of 10-100 ng of fMLP, and the ileal contraction was inhibited by the peptidoleukotriene receptor antagonist FPL-55712 $(0.4 \mu \mathrm{g} / \mathrm{ml})$. Normal hearts and infarcted hearts produced quantitatively similar amounts of the guinea pig ileum-contracting substance in response to fMLP (see Table I). Acutely infarcted hearts (1-d or 4-d) challenged with fMLP also showed a dose-dependent contraction of rabbit aorta and chick rectum (Fig. 3), suggesting that $\mathrm{PGE}_{2}$ and $\mathrm{TxA}_{2}$ were being released. Administration of $\mathrm{AMLP}$ to the normal heart did not result in contraction of either
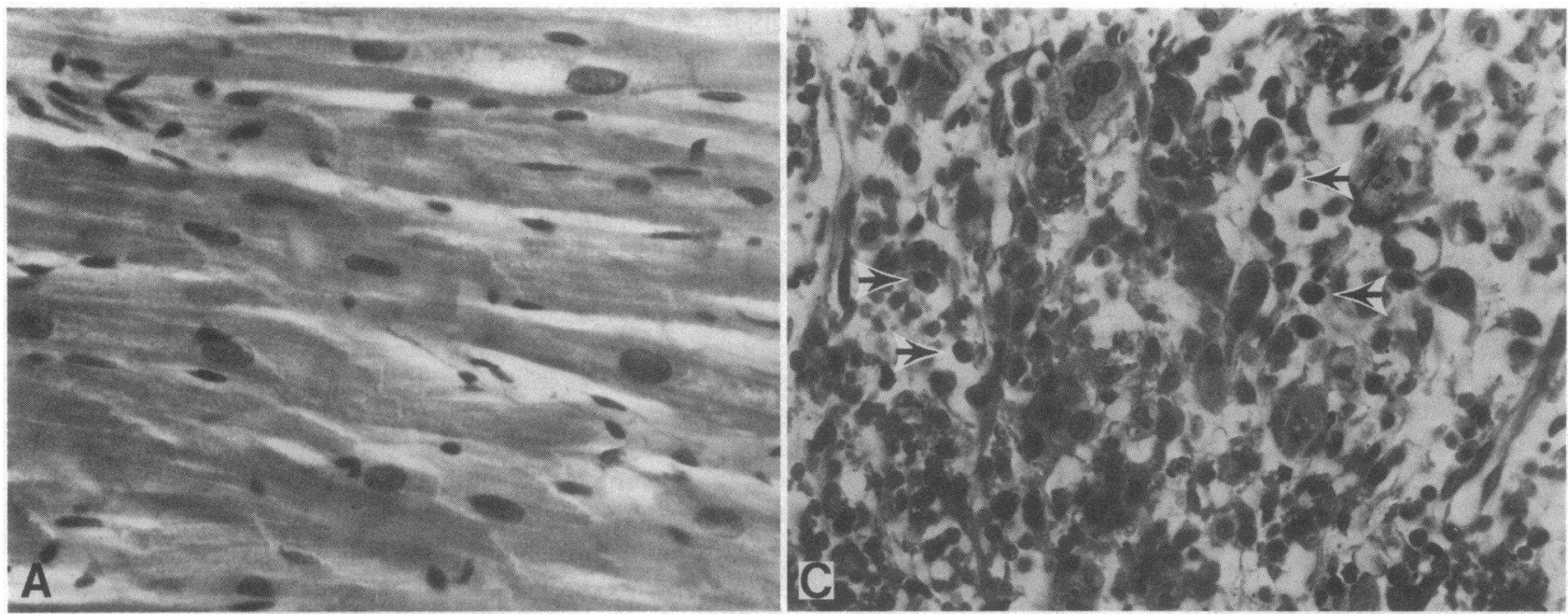

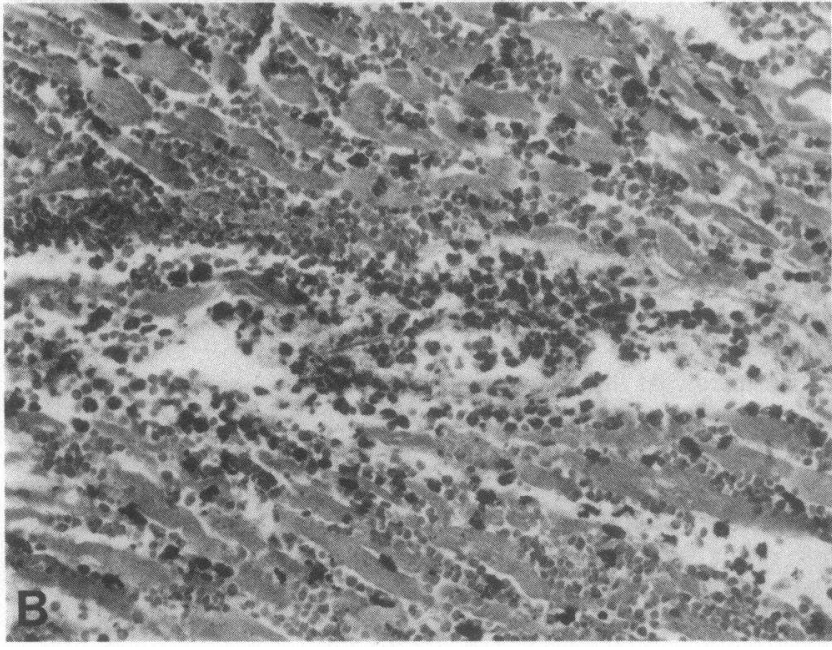

Figure 1. Representative light micrographs of normal and ischemic myocardium following perfusion. $(A)$ Normal myocardium demonstrating mild interstitial edema but no interstitial inflammation or myocyte necrosis. $(B)$ 24-H infarct demonstrating extensive infiltration of neutrophils and interstitial hemorrhage. $(C)$ 4-d infarct con-

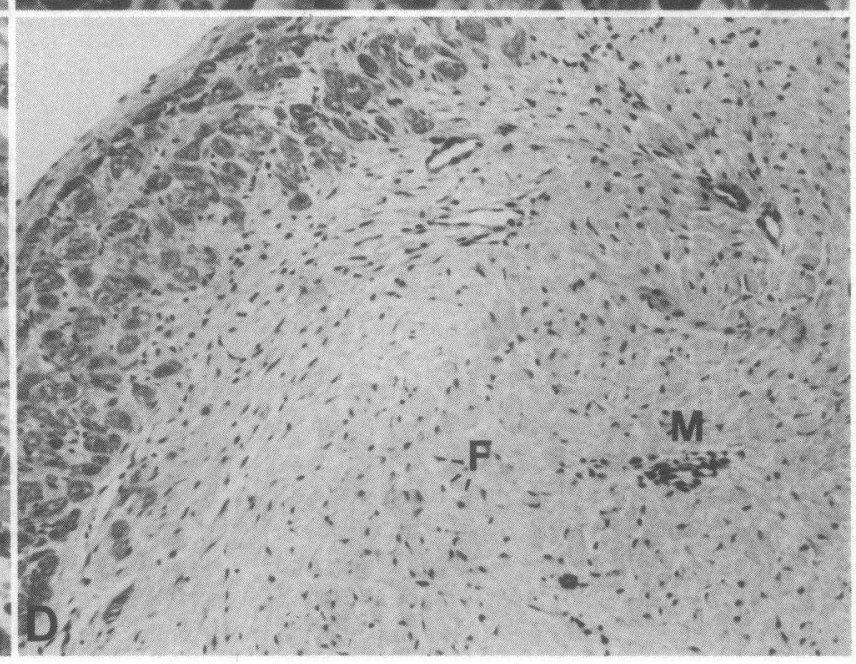

taining numerous macrophages (arrows) resorbing necrotic myocardium. PMNs have largely disappeared. (D) 30-d infarct composed of maturing scar tissue containing fibroblasts $(F)$, and occasional nests of macrophages $(M)$. Original magnification $A$ and $C, \times 800 ; B$, $\times 400 ; D, \times 200$. 


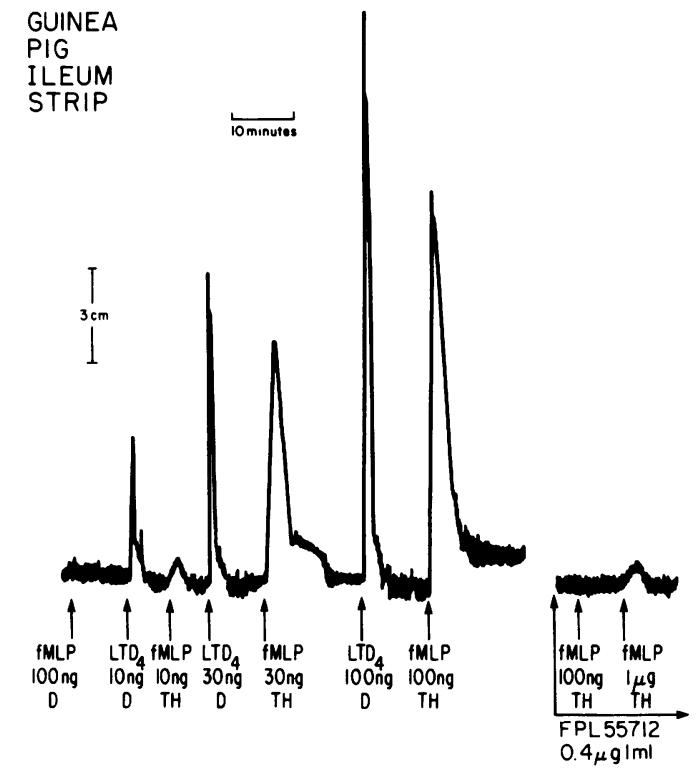

Figure 2. Guinea pig ileum bioassay of peptidoleukotrienes from coronary effluent of 1-d infarcted rabbit heart. fMLP was applied either directly $(D)$ on the assay tissue or through the heart $(T H)$ which was suspended above the assay tissue. Directly applied authentic $\mathrm{LTD}_{4}$ was used to standardize the tissue. The leukotriene receptor antagonist FPL-55712 was applied directly to the tissue.

rabbit aorta or chick rectum. When BK was administered to normal hearts, a dose-dependent contraction of chick rectum, but not rabbit aorta was seen. Acutely infarcted hearts chal- lenged with BK showed a greatly augmented chick rectum contraction as well as a dose-dependent contraction of rabbit aorta, suggesting enhanced $\mathrm{PGE}_{2}$ release and thromboxane release.

The bioassay findings were confirmed and quantitated by specific RIA of the coronary effluent for $\mathrm{PGE}_{2}, \mathrm{TxB}_{2}$ (the stable metabolite of thromboxane $A_{2}$ ), 6-keto-PGF ${ }_{1 \alpha}$ (the stable metabolite of prostacyclin), and peptidoleukotrienes. The RIA results, as well as the quantitative guinea pig ileum bioassay data, are summarized in Table I. These data illustrate that the basal levels of $\mathrm{TxB}_{2}$ and peptidoleukotrienes were similar in normal and infarcted hearts. Basal $\mathrm{PGE}_{2}$ and 6-keto-PGF $1 a$ release, however, was significantly greater in infarcted than in normal hearts. fMLP-induced thromboxane, prostacyclin, and $\mathrm{PGE}_{2}$ release was $\sim 10$-fold greater in acutely infarcted hearts than in normal hearts. At $30 \mathrm{~d}$ following infarction, this response to $\mathrm{AMLP}$ had largely disappeared. Similarly, BKinduced prostacyclin and $\mathrm{PGE}_{2}$ release was 10 -fold greater in acutely infarcted hearts than in normal hearts. BK administration to 30-d infarcted hearts resulted in a level of $\mathrm{PGE}_{2}$ and prostacyclin synthesis intermediate between normal and acutely infarcted hearts. Whereas BK elicited no thromboxane production in normal or 30-d infarcted hearts, it elicited significant amounts of this substance in acutely infarcted hearts. There was no significant difference in agonist stimulated eicosanoid release between $1-d$ and 4- $d$ infarcted hearts. The difference in fMLP-induced $\mathrm{TxB}_{2}$ release between 1-d and 4-d infarcted hearts did, however, approach statistical significance $(P<0.07$ by two-tailed $t$ test). BK did not cause any measurable release of leukotrienes, whereas fMLP induced a quantitatively similar release of peptidoleukotrienes (bioassay and RIA) from normal

Table I. RIA and Bioassay of Coronary Venous Eicosanoids from Normal and Infarcted Rabbit Hearts

\begin{tabular}{|c|c|c|c|c|c|}
\hline & $\mathrm{TxB}_{2}$ & $\mathrm{PGE}_{2}$ & 6-keto- $F_{1 \alpha}$ & LTC $_{4}$ & Leukotriene bioassay \\
\hline & $n g / 5 \min$ & $n g / 5 \min$ & $n g / 5 \min$ & $n g / 5 \min$ & $n g / 5 \min$ \\
\hline \multicolumn{6}{|l|}{ Basal levels } \\
\hline Normal $(n=7)$ & $<4$ & $5 \pm 4$ & $55 \pm 16$ & $3 \pm 2$ & 0 \\
\hline $1-\mathrm{d}(n=7)$ & $6 \pm 2$ & $34 \pm 16$ & $81 \pm 27$ & $2 \pm 1$ & 0 \\
\hline 4-d $(n=7)$ & $6 \pm 4$ & $37 \pm 13^{*}$ & $84 \pm 15$ & $3 \pm 1$ & 0 \\
\hline $30-\mathrm{d}(n=5)$ & $<4$ & $25 \pm 6^{*}$ & $132 \pm 16^{* *}$ & $2 \pm 1$ & 0 \\
\hline \multicolumn{6}{|l|}{ fMLP (100 ng) } \\
\hline Normal $(n=7)$ & $30 \pm 9$ & $27 \pm 10$ & $120 \pm 54$ & $65 \pm 25$ & $51 \pm 17$ \\
\hline $1-\mathrm{d}(n=7)$ & $94 \pm 24^{*}$ & $387 \pm 81^{* *}$ & $1073 \pm 429^{* *}$ & $78 \pm 28$ & $59 \pm 13$ \\
\hline $4-\mathrm{d}(n=7)$ & $235 \pm 66^{* *}$ & $330 \pm 108^{* *}$ & $714 \pm 285^{*}$ & $89 \pm 22$ & $87 \pm 49$ \\
\hline $30-\mathrm{d}(n=5)$ & $42 \pm 8 \ddagger$ & $79 \pm 25 \ddagger$ & $386 \pm 31^{* *}$ & $67 \pm 7$ & $58 \pm 15$ \\
\hline \multicolumn{6}{|l|}{ BK $(1 \mu \mathrm{g})$} \\
\hline Normal $(n=7)$ & $<4$ & $221 \pm 115$ & $667 \pm 201$ & $7 \pm 4$ & 0 \\
\hline $1-\mathrm{d}(n=7)$ & $20 \pm 6^{* *}$ & $2938 \pm 712^{* *}$ & $3692 \pm 897^{*}$ & $6 \pm 1$ & 0 \\
\hline 4-d $(n=7)$ & $53 \pm 22^{* *}$ & $2512 \pm 383^{* *}$ & $5229 \pm 1125^{*}$ & $12 \pm 4$ & 0 \\
\hline $30-\mathrm{d}(n=5)$ & $4 \pm 2 \ddagger$ & $628 \pm 136^{*} \ddagger$ & $2140 \pm 387^{* *} \ddagger$ & - & 0 \\
\hline
\end{tabular}

Samples of coronary venous effluent were collected for $5 \mathrm{~min}(125 \mathrm{ml})$ before agonist stimulation (basal), or immediately following intracoronary administration of either fMLP or BK. Collections were made from isolated perfused noninfarcted (normal) hearts or from hearts 1,4 , or 30 d following myocardial infarction. Aliquots of the effluent were radioimmunoassayed for $\mathrm{TxB}_{2}$, the stable metabolite of $\mathrm{TxA}_{2}, \mathrm{PGE}_{2}, 6-\mathrm{keto}$ $\mathrm{PGF}_{1 \alpha}$, the stable metabolite of prostacyclin, or $\mathrm{LTC}_{4}$. The $\mathrm{LTC}_{4}$ antibody cross-reacted significantly with $\mathrm{LTD}_{4}$; the values presented therefore represent total peptidoleukotrienes. Bioassay data is from a guinea pig ileum superfusion assay. Values were calculated by extrapolating the

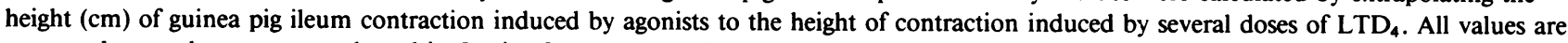
expressed as total nanograms released in $5 \mathrm{~min} \pm$ SEM. A two-tailed $t$ test for unpaired data was used to compare infarcted hearts with normal hearts. ${ }^{*} P<0.05 ;{ }^{* *} P<0.01$. A two-tailed $t$ test for unpaired data was also used to compare 30 -day infarcted hearts to 4-day infarcted hearts. $¥ P<0.05$. 


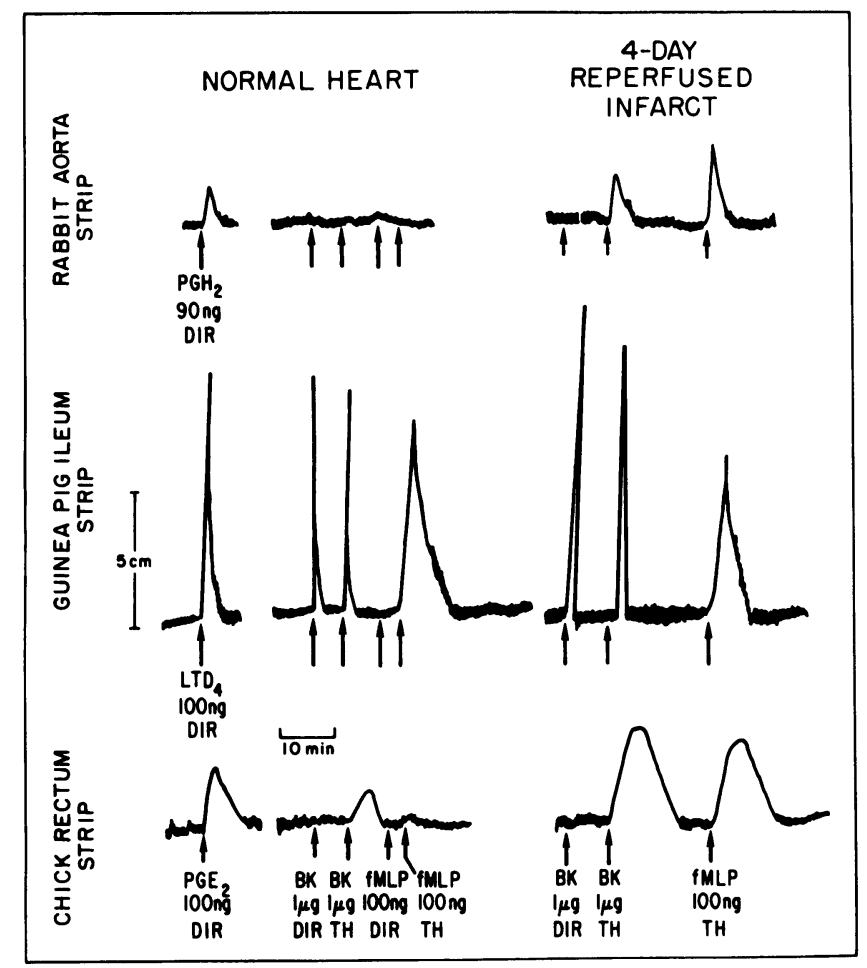

Figure 3. Superfusion bioassay of coronary effluent from normal and 4-d infarcted rabbit hearts. Rabbit aorta strips were used to detect $\mathrm{TxA}_{2}$-like activity and were standardized with direct application $(D I R)$ of $\mathrm{PGH}_{2}$. Guinea pig ileum strips were used to detect peptidoleukotriene-like activity and were standardized with authentic LTD . Chick rectum strips were used to detect $\mathrm{PGE}_{2}$-like activity and were standardized with $\mathrm{PGE}_{2}$. The agonists BK and fMLP were applied (indicated by arrows) either directly $(D I R)$ to the tissue or through the heart $(T H)$, which was suspended immediately above the assay tissues.

and infarcted hearts. The dose dependency of cyclooxygenase product release is shown in Table II.

HPLC. To confirm that the guinea pig ileum-contracting substance released by heart was a leukotriene and to identify which species of leukotrienes were being released, coronary effluent was analyzed by HPLC. As seen in Fig. 4, basal cardiac effluent from normal hearts showed no leukotriene peaks. When the effluent from fMLP-stimulated hearts was chromatographed, peaks which co-migrated with authentic standards of $\mathrm{LTB}_{4}, \mathrm{LTC}_{4}$, and $\mathrm{LTD}_{4}$ were obtained. Chromatograms of basal and fMLP stimulated effluent from normal, 1-d, and 4-d infarcted hearts were qualitatively similar. BKstimulated effluent showed no leukotriene peaks (data not shown).

The peak that co-migrated with $\mathrm{LTD}_{4}$ on HPLC had an ultraviolet spectrum that was characteristic of the peptidoleukotrienes, with UV peaks at 270, 280, and $290 \mathrm{~nm}$ (24). The $\mathrm{LTB}_{4}$ peak showed the characteristic spectrum with peaks at 260,270 , and $280 \mathrm{~nm}(25)$. An adequate spectrum of $\mathrm{LTC}_{4}$ could not be obtained because this peak did not completely separate from material eluting with the solvent front.

Effects of endogenously produced eicosanoids on coronary vascular resistance. Administration of fMLP to infarcted hearts resulted in the release of several vasoactive eicosanoids. To determine the effect of each product on vasomotor tone, we measured the change in coronary perfusion pressure (under constant flow conditions) elicited by FMLP and BK in the presence of the leukotriene receptor antagonist FPL-55712, the thromboxane synthetase inhibitor OKY-1581, or the cyclooxygenase inhibitor indomethacin. We studied seven normal hearts, four 1-d infarcted hearts and five 4-d infarcted hearts. Normal hearts challenged with fMLP (100 ng) showed a $5.6 \pm 2.1 \%$ (mean $\pm S E M$ ) increase in coronary perfusion pressure (CPP); $1-d$ infarcted hearts showed a $15.0 \pm 4.1 \%$ increase in CPP $(P<0.05$ by two-tailed $t$ test when compared with normal hearts); and 4-d infarcted hearts showed a $21.2 \pm 2.5 \%$ increase in CPP ( $P<0.001$ compared with normal hearts). The base-line coronary perfusion pressures were similar in normal and infarcted hearts; base-line CPP for all experiments was $78.3 \pm 4.1$ (mean \pm SEM) $\mathrm{mmHg}$. Interestingly, the coronary vasoconstriction was not inhibited by OKY-1581 or indomethacin, but was completely abolished by FPL-55712. In some experiments, the duration but not the magnitude of coronary vasoconstriction was reduced by OKY-1581, and in two of five 4-d infarcted hearts, fMLP-induced vasoconstriction was facilitated by indomethacin. A representative tracing from these experiments is shown in Fig. 5.

BK (300 $\mathrm{ng}$ ) produced a vasodilatation in both normal and infarcted hearts. This vasodilatation was not inhibited by OKY-1581 or FPL-55712, but was abolished by indomethacin.

Table II. Dose-Response of Prostaglandin Release by BK and fMLP in Normal and Infarcted Rabbit Hearts

\begin{tabular}{|c|c|c|c|c|c|c|c|c|c|}
\hline & \multicolumn{3}{|l|}{$\mathrm{T} \times \mathrm{B}_{2}$} & \multicolumn{3}{|l|}{$\mathrm{PGE}_{2}$} & \multicolumn{3}{|c|}{ 6-keto-PGF $F_{1 \alpha}$} \\
\hline & $\begin{array}{l}\text { Normal } \\
(n=7)\end{array}$ & $\begin{array}{l}1-d \\
(n=7)\end{array}$ & $\begin{array}{l}4-d \\
(n=7)\end{array}$ & $\begin{array}{l}\text { Normal } \\
(n=7)\end{array}$ & $\begin{array}{l}1-d \\
(n=7)\end{array}$ & $\begin{array}{l}4-d \\
(n=7)\end{array}$ & $\begin{array}{l}\text { Normal } \\
(n=7)\end{array}$ & $\begin{array}{l}1-d \\
(n=7)\end{array}$ & $\begin{array}{l}\text { 4-d } \\
(n=7)\end{array}$ \\
\hline \multicolumn{10}{|c|}{ [BK] (ng) } \\
\hline 100 & $<4$ & $9 \pm 5$ & $15 \pm 9$ & $74 \pm 20$ & $202 \pm 35^{*}$ & $730 \pm 172^{*}$ & $341 \pm 57$ & $653 \pm 155$ & $1625 \pm 294^{*}$ \\
\hline 300 & $<4$ & $4 \pm 2$ & $37 \pm 31$ & $62 \pm 16$ & $534 \pm 153^{*}$ & $1752 \pm 587^{* *}$ & $286 \pm 60$ & $1589 \pm 329 *$ & $3081 \pm 683^{*}$ \\
\hline 1,000 & $<4$ & $20 \pm 6^{*}$ & $53 \pm 22^{*}$ & $220 \pm 116$ & $2938 \pm 716^{*}$ & $2512 \pm 38^{* *}$ & $667 \pm 201$ & $3692 \pm 897^{*}$ & $5229 \pm 1126^{* *}$ \\
\hline \multicolumn{10}{|c|}{$[f M L P](n g)$} \\
\hline 10 & $1 \pm 1$ & $10 \pm 4$ & $10 \pm 9$ & $7 \pm 4$ & $56 \pm 12^{*}$ & $110 \pm 52^{*}$ & $75 \pm 30$ & $148 \pm 40$ & $175 \pm 67$ \\
\hline 30 & $12 \pm 7$ & $39 \pm 11$ & $53 \pm 25^{*}$ & $19 \pm 9$ & $103 \pm 32^{*}$ & $100 \pm 25^{*}$ & $61 \pm 16$ & $209 \pm 37^{*}$ & $264 \pm 78^{*}$ \\
\hline 100 & $30 \pm 9$ & $94 \pm 23^{*}$ & $235 \pm 66^{*}$ & $27 \pm 10$ & $397 \pm 81^{*}$ & $330 \pm 108^{*}$ & $120 \pm 54$ & $1073 \pm 429 *$ & $714 \pm 285^{*}$ \\
\hline
\end{tabular}

RIA of $\mathrm{TxB}_{2}, \mathrm{PGE}_{2}$, and 6-keto-PGF ${ }_{1 a}$ is as described in Table I. Normal, noninfarcted hearts; 1-d and 4-d refers to the number of days of convalescence following myocardial infarction. Hearts were challenged with bolus administration of either BK or fMLP. All values expressed are nanograms produced in the 5-min collection period \pm SEM. A two tailed $t$ test for unpaired data was used to compare infarcted hearts with normal hearts at each dose. ${ }^{*} P<0.05$. $* * P<0.01$. 


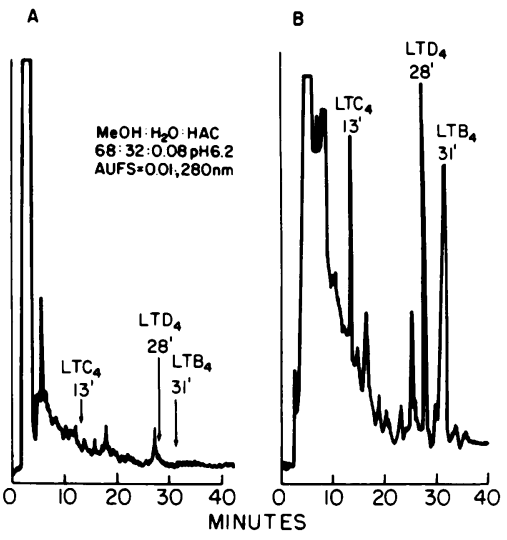

Figure 4. Reverse phase HPLC of basal and AMLP-stimulated coronary effluent from the normal rabbit heart. $125-\mathrm{ml}$ samples of coronary effluent collected either before stimulation $(A)$ or immediately following intracoronary administration of $\mathrm{AMLP}(B)$ were extracted and concentrated on an open-bed reverse phase octadecylsilyl column. The concentrated samples were applied to a C-18, 5- $\mu \mathrm{m}$ reverse phase octadecylsilyl HPLC column and leukotrienes were detected by their UV absorbance at $280 \mathrm{~nm}$. The migration of authentic leukotriene standards is indicated by arrows at their retention times.

The order of inhibitor administration was varied in each experiment, and did not influence the results.

\section{Discussion}

Previous work has shown that exogenously administered $\mathrm{LTC}_{4}$ and $\mathrm{LTD}_{4}$ are coronary vasoconstrictors in a variety of species, and that leukotriene-mediated vasoconstriction is inhibited by the leukotriene receptor antagonist FPL-55712 (16, 18, 19). The present results demonstrate the agonist-stimulated release of significant quantities of endogenously produced $\mathrm{LTB}_{4}$, $\mathrm{LTC}_{4}$, and $\mathrm{LTD}_{4}$ into the coronary venous effluent of rabbit hearts. Surprisingly, normal and infarcted hearts released similar quantities of peptidoleukotrienes into the coronary venous effluent. The cellular source of leukotrienes in normal heart is suggested by previous investigations in the guinea pig model of cardiac anaphylaxis. Sensitized guinea pig hearts challenged with antigen release immunoassayable $\mathrm{LTC}_{4}$ into the cardiac effluent (26). Since large numbers of mast cells are present in the heart (27), it is conceivable that IMLP-induced leukotriene release from noninfarcted hearts is analagous to cardiac anaphylaxis and is mediated by mast cells (28).

In infarcted, but not normal rabbit hearts, fMLP elicited a significant coronary vasoconstriction that was specifically antagonized by FPL-55712. The dissociation between quantity of peptidoleukotriene release and leukotriene-mediated vasoconstriction can be explained in several ways. Normal hearts challenged with fMLP release relatively large quantities of leukotrienes, which could mask small amounts of product synthesis by inflammatory cells. Mast cells are known to be localized around venules. If these cells are the cellular source of leukotriene synthesis, product synthesis at this site would be distal to arteriolar resistance elements. Thus, production of large amounts of leukotrienes would cause only a small change in coronary resistance. This possibility is supported by the preliminary finding that when coronary venous effluent from noninfarcted fMLP-stimulated hearts is reperfused through the coronary arteries, a significant coronary vasoconstriction occurs that is abolished by FPL-55712 ( $n .=2$, data not shown). In contrast, small amounts of synthesis by inflammatory cells in infarcted tissue could produce high local concentrations of leukotrienes and exert a regional vasoconstrictive effect. Regardless of the cellular source of leukotriene synthesis, the data suggest that $\mathrm{MLP}$ induces leukotriene synthesis at a different (or additional) site in infarcted hearts than in normal hearts.

The hypothesis that lipoxygenase metabolites of AA contribute to tissue injury in myocardial infarction is supported by several lines of evidence. Dual inhibitors of lipoxygenase and cyclooxygenase such as $\mathrm{BW}-755 \mathrm{C}(9,10)$ reduce both the size of experimental canine myocardial infarcts and the magnitude of PMN infiltration. In contrast, pure cyclooxygenase inhibitors, such as indomethacin (13), aspirin (11), and naproxen (12) do not reduce infarct size. Mullane et al. (2) have recently shown that infarcted canine tissue produces ten times

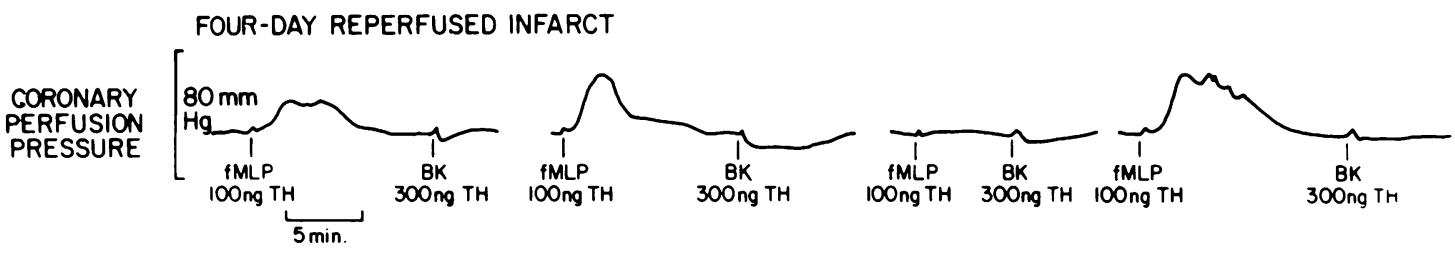

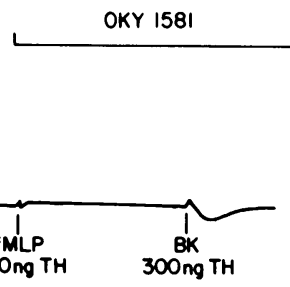

Figure 5. Effects of agonist-stimulated eicosanoids on coronary vascular resistance in normal and 4-d infarcted rabbit hearts. Hearts were retrogradely perfused at a constant flow of $25 \mathrm{ml} / \mathrm{min}$ and coronary perfusion pressure was monitored via a sidearm in the perfusion apparatus. fMLP and BK were administered as bolus injections (0.1 $\mathrm{ml})$ directly above the coronary ostia $(T H)$. The thromboxane syn-

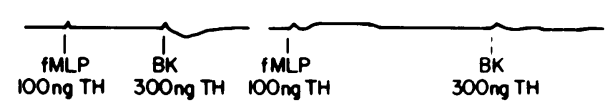

thetase inhibitor OKY $-1581(0.1 \mathrm{mg} / \mathrm{ml})$, the leukotriene receptor antagonist FPL-55712 $(0.4 \mu \mathrm{g} / \mathrm{ml})$, and indomethacin $(1.0 \mu \mathrm{g} / \mathrm{ml})$ were added to the perfusion fluid. Sufficient time was allowed between administration of inhibitors for full recovery of the vascular response to agonists. The tracings from the 4-d infarcted heart and the normal heart are each from a single representative experiment. 
more 12-HETE than does adjacent normal tissue. The function of 12-HETE in canine myocardial infarction is unknown. 12-HETE has minimal chemotactic activity (29) and is a weak coronary vasoconstrictor (30).

$\mathrm{LTB}_{4}$ is an extremely potent chemotactic agent and is produced in large amounts by PMNs (31). Our demonstration that $\mathrm{LTB}_{4}$ is produced by heart (Fig. $4 \mathrm{~B}$ ) suggests a likely chemotactic lipoxygenase product in myocardial infarction. Myocardial injury may serve as an agonist, stimulating the heart's potential to produce $\mathrm{LTB}_{4}$, which could serve as the initial chemotactic signal for PMNs. Inhibition of $\mathrm{LTB}_{4}$ synthesis may explain the reduced inflammatory cell invasion seen with cardioprotective agents such as BW-755C. Production of the potent coronary vasoconstrictor leukotrienes, $\mathrm{LTC}_{4}$ and $\mathrm{LTD}_{4}$, may increase myocardial tissue injury by exacerbating ischemia. Inhibition of the synthesis of these products by lipoxygenase inhibitors may also contribute to reduced infarct size.

Stimulation with fMLP caused far greater production of cyclooxygenase products in acutely infarcted hearts than in normal hearts. Histologic analysis showed that the predominant inflammatory cell types are polymorphonuclear leukocytes in 1-d infarcts and macrophages in 4-d infarcts. Both of these cell types have been shown to have receptors for formylated peptides (32-34). Macrophages and PMNs have also been shown to produce $\mathrm{TxA}_{2}$ and $\mathrm{PGE}_{2}$ in response to various stimuli (35), and, therefore, may be the cells responsible for synthesis of these products. While prostacyclin can be produced by macrophages (15), PMNs are unlikely to be the source of the high levels of prostacyclin seen in these experiments (36). fMLP may activate leukocyte phospholipases to release AA, which is subsequently metabolized by coronary vascular endothelium to prostacyclin and $\mathrm{PGE}_{2}$ (37). The association of enhanced AA metabolism with inflammatory cell invasion is supported by the data showing a decrease in fMLP-induced cyclooxygenase metabolite synthesis and decreased inflammatory cell infiltrate in $30-\mathrm{d}$ infarcted hearts. This association is further strengthened by the observation that the increased synthetic capacity for thromboxane, prostacyclin, and $\mathrm{PGE}_{2}$ is localized to the infarcted zone in canine myocardial infarction (38).

BK also elicited increased release of prostacyclin, $\mathrm{PGE}_{2}$, and thromboxane in acutely infarcted hearts. Fibroblasts and endothelial cells acting in concert could account for the increased production of $\mathrm{PGI}_{2}$ and $\mathrm{PGE}_{2}$ in infarcted hearts. The cellular source of $\mathrm{BK}$-induced thromboxane release is unclear. In another model of inflammation, the rabbit hydronephrotic kidney, the ability of BK to cause thromboxane release has clearly been associated with the presence of mononuclear cells in association with interstitial fibroblasts $(39,40)$. An interaction between mononuclear cells and fibroblasts may be necessary for BK to cause synthesis and release of thromboxane. This hypothesis is supported by the data showing elimination of BK-induced thromboxane release in association with the disappearance of mononuclear cells $30 \mathrm{~d}$ after myocardial infarction.

This study addresses the synthesis of eicosanoids in an early reperfusion model of myocardial infarction. A reperfusion model was selected for these experiments because a patent coronary artery maximizes access of exogenously administered agonists to the infarcted zone and because reperfusion models show greater inflammatory cell invasion than do permanent coronary ligation models (41). While the data in this paper can only be applied to reperfused myocardial infarction, the histologic presence of inflammatory cells in the infarcted zone of hearts with permanent coronary ligation suggests that enhanced AA metabolism would also occur in this model. This contention is supported by preliminary evidence from our laboratory showing enhanced production of $\mathrm{TxB}_{2}, \mathrm{PGE}_{2}$, and prostacyclin in response to fMLP in rabbit hearts with permanent coronary ligation.

In summary, a new model of myocardial infarction, the isolated perfused infarcted rabbit heart, has been described. Using this preparation, we have demonstrated cardiac production of $\mathrm{LTB}_{4}, \mathrm{LTC}_{4}$, and $\mathrm{LTD}_{4}$ as well as exaggerated synthesis of $\mathrm{TxA}_{2}, \mathrm{PGE}_{2}$, and prostacyclin by acutely infarcted hearts. Furthermore, it has been demonstrated that endogenously produced peptidoleukotrienes are potent coronary vasoconstrictors in infarcted hearts. We speculate that cardiac synthesis of the coronary vasoconstrictor leukotrienes, $\mathrm{LTC}_{4}$ and $\mathrm{LTD}_{4}$, may exacerbate tissue injury in myocardial infarction and contribute to complications such as postinfarction angina and infarct extension.

\section{Acknowledgments}

We are grateful for the skillful preparation of the manuscript by Mary Rogers and Linda Hammond.

This research was supported by National Institutes of Health grants HL17646 to Dr. Needleman and HL311922 to Dr. Jakschik.

\section{References}

1. Romson, J. L., B. G. Hook, S. L. Kunkel, G. D. Abrams, M. A. Schork, and B. R. Lucchesi. 1983. Reduction of the extent of ischemic myocardial injury by neutrophil depletion in the dog. Circulation. 67:1016-1023.

2. Mullane, K. M., N. Read, J. A. Salmon, and S. Moncada. 1984. Role of leukocytes in acute myocardial infarction in anesthetized dogs: relationship to myocardial salvage by anti-inflammatory drugs. $J$. Pharmacol. Exp. Ther. 228:510-522.

3. Mallory, G., P. White, and T. Salcedo-Salgar. 1939. The speed of healing of myocardial infarction. A study of the pathologic anatomy in seventy-two cases. Am. Heart J. 18:647-671.

4. Fridovich, I. 1978. The biology of oxygen radicals. Science (Wash. DC). 201:875-880.

5. Weissmann, G., J. Smolen, and H. Korchak. 1980. Release of inflammatory mediators from stimulated neutrophils. N. Engl. J. Med. 303:27-34.

6. Snyderman, R., and E. Goetzl. 1981. Molecular and cellular mechanisms of leukocyte chemotaxis. Science (Wash. DC). 213:830837.

7. Samuelsson, B., E. Goldyne, E. Granstrom, M. Hamberg, S. Hammarstrom, and C. Malmsten. 1978. Prostaglandins and thromboxanes. Annu. Rev. Biochem. 47:997-1029.

8. Lewis, R. A., and K. F. Austen. 1984. The biologically active leukotrienes. J. Clin. Invest. 73:889-897.

9. Mullane, K. M., and S. Moncada. 1982. The salvage of ischaemic myocardium by BW-755C in anaesthetized dogs. Prostaglandins. 24: 255-266.

10. Jolly, S. R., and B. R. Lucchesi. 1983. Effect of BW-755C in an occlusion-reperfusion model of ischemic myocardial injury. Am. Heart J. 106:8-13.

11. Bonow, R. O., L. C. Lipson, F. H. Sheehan, N. L. Capurro, J. M. Isner, W. C. Roberts, R. E. Goldstein, and S. E. Epstein. 1981. Lack of effect of aspirin on myocardial infarct size in the dog. Am. J. Cardiol. 47:258-264. 
12. Bolli, R., R. E. Goldstein, N. Davenport, and S. E. Epstein. 1981. Influence of sulfinpyrazone and naproxen on infarct size in the dog. Am. J. Cardiol. 47:841-847.

13. Jugdutt, B. I., G. M. Hutchins, B. J. Bulkley, B. Pitt, and L. C. Becker. 1979. Effect of indomethacin on collateral blood flow and infarct size in the conscious dog. Circulation. 59:734-743.

14. Borgeat, P., and B. Samuelsson. 1979. Transformation of arachidonic acid by rabbit polymorphonuclear leukocytes. J. Biol. Chem. 254:2643-2646.

15. Scott, W. A., N. A. Pawlowski, M. Andreach, and Z. A. Cohn. 1982. Resting macrophages produce distinct metabolites from exogenous arachidonic acid. J. Exp. Med. 155:535-547.

16. Letts, L. G., and P. J. Piper. 1982. The actions of leukotrienes $\mathrm{C}_{4}$ and $\mathrm{D}_{4}$ on guinea pig isolated hearts. Br. J. Pharmacol. 76:169176.

17. Terashita, Z., H. Fukui, M. Hirata, S. Terao, S. Ohkawa, K. Nishikawa, and S. Kikuchi. 1981. Coronary vasoconstriction and $\mathrm{PGI}_{2}$ release by leukotrienes in isolated guinea pig hearts. Eur. J. Pharmacol. 73:357-361.

18. Michelassi, F., L. Landa, R. D. Hill, E. Lowenstein, W. D. Watkins, A. J. Petkau, and W. M. Zapol. 1982. Leukotriene $\mathrm{D}_{4}$ : a potent coronary artery vasoconstrictor associated with impaired ventricular contraction. Science (Wash. DC). 217:841-843.

19. Burke, J. A., R. Levi, Z. Guo, and E. J. Corey. 1982. Leukotrienes $C_{4}, D_{4}$ and $E_{4}$ : effects on human and guinea pig cardiac preparations in vitro. J. Pharmacol. Exp. Ther. 221:235-241.

20. Needleman, P., S. L. Key, S. E. Denny, P. C. Isakson, and G. R. Marshall. 1975. Mechanism and modification of bradykinininduced coronary vasodilatation. Proc. Nat. Acad. Sci. USA. 72:20602063.

21. Gilmore, N., J. R. Vane, and J. H. Wyllie. 1968. Prostaglandins released by the spleen. Nature (Lond.). 218:1135-1140.

22. Powell, W. S. 1982. Rapid extraction of arachidonic acid metabolites from biological samples using octadecylsilyl silica. Methods Enzymol. 86:467-477.

23. Reingold, D. F., K. Watters, S. Holmberg, and P. Needleman. 1981. Differential biosynthesis of prostaglandins by hydronephrotic rabbit and cat kidneys. J. Pharmacol. Exp. Ther. 216:510-515.

24. Murphy, R. C., S. Hammarstrom, and B. Samuelsson. 1979. Leukotriene C: a slow reacting substance from murine mastocytoma cells. Proc. Natl. Acad. Sci. USA. 76:4275-4279.

25. Borgeat, P., and B. Samuelsson. 1979. Metabolism of arachidonic acid in polymorphonuclear leukocytes. J. Biol. Chem. 254:7865-7869.

26. Aehringhaus, U., B. A. Peskar, H. R. Wittenberg, and R. H. Wolbling. 1983. Effect of inhibition of synthesis and receptor antagonism of SRS-A in cardiac anaphylaxis. Br. J. Pharmacol. 80:73-80.

27. Pollack, O. J. 1957. Mast cells in the circulatory system of man. Circulation. 16:1084-1089.
28. Allan, G., J. H. Zavcez, and R. Levi. 1977. Release of prostaglandins and SRS-A during cardiac anaphylaxis. Bull. NY Acad. Med. 53:304.

29. Palmer, R. M. J., R. J. Stepney, G. A. Higgs, and K. E. Eakins. 1980. Chemokinetic activity of arachidonic acid lipoxygenase products on leukocytes of different species. Prostaglandins. 20:411-418.

30. Trachte, G. J., A. M. Lefer, D. Aharony, and J. B. Smith. 1979. Potent constriction of cat coronary arteries by hydroperoxides of arachidonic acid and its blockade by anti-inflammatory agents. Prostaglandins. 18:909-914.

31. Ford-Hutchinson, A. W., A. M. Bray, M. V. Doig, M. E. Shipley, and M. J. H. Smith. 1980. Leukotriene B , a potent chemokinetic and aggregating substance released from polymorphonuclear leukocytes. Nature (Lond.). 286:264-265.

32. Williams, L. T., R. Snyderman, M. C. Pike, and R. J. Lefkowitz. 1977. Specific receptors for chemotactic peptides on human polymorphonuclear leukocytes. Proc. Natl. Acad. Sci. USA. 74:12041208.

33. Aswanikumar, S., B. Corcoran, and E. Schiffmann. 1977. Demonstration of a receptor on rabbit neutrophils for chemotactic peptides. Biochem. Biophys. Res. Commun. 74:810-817.

34. Snyderman, R., and E. J. Fudman. 1980. Demonstration of a chemotactic factor receptor on macrophages. J. Immunol. 124:27542757.

35. Morley, J., M. A. Bray, R. W. Jones, D. H. Nugteren, and D. A. van Dorp. 1979. Prostaglandin and thromboxane production by human and guinea pig macrophages and leukocytes. Prostaglandins. 17:730-736.

36. Bokoch, G. M., and P. W. Reed. 1980. Stimulation of arachidonic acid metabolism in the polymorphonuclear leukocyte by an $N$-formylated peptide. J. Biol. Chem. 255:10223-10226.

37. Gerritsen, M. E., and C. D. Cheli. 1983. Arachidonic acid and prostaglandin endoperoxide metabolism in isolated rabbit and coronary microvessels and isolated and cultivated microvessel endothelial cells. J. Clin. Invest. 72:1658-1671.

38. McCluskey, E. R., P. B. Corr, B. I. Lee, J. E. Saffitz, and P. Needleman. 1982. The arachidonic acid metabolic capacity of canine myocardium is increased during healing of acute myocardial infarction. Circ. Res. 51:743-750.

39. Okegawa, T., P. E. Jonas, K. DeSchryver, A. Kawasaki, and P. Needleman. 1983. Metabolic and cellular alterations underlying the exaggerated renal prostaglandin and thromboxane synthesis in ureter obstruction in rabbits. J. Clin. Invest. 71:81-90.

40. Jonas, P. E., K. M. Leahy, K. DeSchryver-Kecskemeti, and P. Needleman. 1984. Cellular interactions and exaggerated arachidonic acid metabolism in rabbit renal injury. J. Leuk. Biol. 35:55-64.

41. Sommers, H. M., and R. B. Jennings. 1964. Experimental acute myocardial infarction. Lab. Invest. 13:1491-1503. 